\title{
Ionic liquid based pretreatment of lignocellulosic biomass for enhanced bioconversion
}

\author{
Zeba Usmani ${ }^{\mathrm{a}}$, Minaxi Sharma ${ }^{\mathrm{b}}$, Pratishtha Gupta ${ }^{\mathrm{c}}$, Yevgen Karpichev ${ }^{\mathrm{a}}$, Nicholas \\ Gathergood $^{\mathrm{a}, \mathrm{d}}$, Rajeev Bhat ${ }^{\mathrm{b}}$, Vijai Kumar Gupta ${ }^{\mathrm{a}, \mathrm{b}^{*}}$
}

aDepartment of Chemistry and Biotechnology, Tallinn University of Technology, 12618 Tallinn, Estonia

${ }^{b}$ ERA Chair for Food (By-)Products Valorization Technologies (VALORTECH), Estonian University of Life Sciences, 51014 Tartu, Estonia

${ }^{\mathrm{c}}$ Applied Microbiology Laboratory, Department of Environmental Science and Engineering, Indian Institute of Technology (ISM), Dhanbad- 826001, India

${ }^{\mathrm{d}}$ School of Chemistry, University of Lincoln, Joseph Banks Laboratories,

Green Lane, Lincoln, Lincolnshire LN6 7DL, UK

*Corresponding author email: vijaifzd@gmail.com 


\begin{abstract}
Lignocellulosic biomass is the most plentiful renewable biomolecule and an alternative bioresource for the production of biofuels and biochemicals in biorefineries. But biomass recalcitrance is a bottleneck in their usage, thus necessitating their pretreatment for hydrolysis. Most pretreatment technologies, result in toxic by-products or have lower yield. Ionic liquids (ILs) have successfully advanced as 'greener and recyclable' alternatives to volatile organic solvents for lignocellulosic biomass dissolution. This review covers recent developments made in usage of IL-based techniques with focus on biomass breakdown mechanism, process parameter design, impact of cation and anion groups, and the advantageous impact of ILs on the subsequent processing of the fractionated biomass. Progress and barriers for large-scale commercial usage of ILs in emerging biorefineries were critically evaluated using the principles of economies of scale and green chemistry in an environmentally sustainable way.
\end{abstract}

Keywords: Lignocellulosic biomass, Ionic liquids, Pretreatment, Enzymatic hydrolysis, Biorefinery 


\section{Introduction}

The population of the world today is $\sim 1900$-times the size of what it was 12 thousand years ago when it was around 4 million - half of today's population of London. This rapid growth is creating tremendous usage of natural resources, energy and chemicals. In 2018, global energy requirement grew by $2.3 \%$, its fastest speed in the past decade. The surge in the cost of fuel energy, need to reduce dependence on traditional chemicals that impact the environment, and the changing societal and cultural value of the world is challenging us as humanity to look towards efficient usage of renewable resources and to accelerate efforts to upcycle traditional organic wastes. Lignocellulosic biomass is a natural vessel for amassing solar energy and hence presents itself as an important renewable resource for raw material and energy (Bhatia et al., 2019a; Bhatia et al., 2019b). Plants convert approximately 4,500 Exa Joules (EJ) of solar energy annually (Ralph, 2014) and convert nearly 120 Giga Tonnes of carbon from the atmosphere into biomass - nearly eight times the global energy demand. Approximately $50 \%$ of the global biomass is made up of lignocellulose, making it the most available organic compound in the biosphere. Various industries such as food, pharmaceutical, and cosmetics exploit lignocellulose in their production chain. Lignocellulose also serves as a substrate in the synthesis of bioethanol (Naghshbandi et al., 2019), beauty masks, curative chows, fillers for thermoplastic composite materials and many other products (de Paula et al., 2019).

The physical properties of lignocellulosic material make it a biologically renewable and sustainable source of organic carbon and thus it is a possible raw material for renewable biofuel manufacture that can serve as an alternate to fossil fuels. Additionally, there has been a growing interest in the transfiguration of lignocellulosic biomass to manufacture green chemicals (Kang and Zhang, 2018; de Paula et al., 2019). However, usage of lignocellulosic biomass as feed material for biofuel production or synthesis of green platform chemicals is 
not straightforward in its natural physical form. Thus, pretreatment becomes a vital step in the process of obtaining/producing useful end products from lignocellulosic biomass. Pretreatment ensures to decrease crystallinity and heighten the porosity of the lignocellulosic biomass, which makes it more susceptible to further chemical reactions and usage across multiple industries. A lot of processes have been developed over the years for lignocellulosic biomass pretreatment, each with its own merits under varying conditions. Ionic liquids (ILs) have gained significant traction in pretreatment process due to their unique and green properties combined with their potential to completely breakdown and dissolve lignocellulosic materials (Sun et al., 2017; Bhatia et al., 2019a).

The focus of this review is to explore the current undertakings in pretreatment of lignocellulosic biomass using ILs, highlighting their green nature, and advantageous impact in further alteration of lignocellulosic biomass components thus derived into value-added end products. While most available reviews focus on the pretreatment step using ILs, not many have brought forward the advantages that ILs bring when combined with other pretreatment materials, as well as the benefit that ILs bring to the subsequent processes after pretreatment step. Towards this the focus is to bring attention towards recent works published for using ILs in conjunction with alkali and acids and enhanced enzymatic hydrolysis via single-step hydrolysis studies performed on various lignocellulosic biomass feedstock once pretreated with ILs. The review also sheds light on cost-benefit analysis of usage of ILs through some of the techno-economic studies performed to highlight the feasibility of using ILs in large-scale pretreatment plants.

\section{Lignocellulosic Biomass}

Lignocellulosic biomass is a major component in agriculture, forestry, and fruit and vegetable waste. The lignocellulosic materials comprise of trees, stems, grass, and flowers along with quick growth high energy plants e.g., poplar, miscanthus and energetic willow. Additionally, 
agricultural waste such as corncob, corn and cereal straw, sugar beets parts, potato haulms, rapeseed and sunflowers oil pressing residue, paper industry residue, sawmills, paper waste are the major supplies of lignocellulosic materials (Hassan et al., 2018; Hernandez-Beltran et al., 2019). Forestry wastes such as stems, stumps, branches, residues from wood industry are also a good supply of lignocellulosic biomass. Organic wastes such as municipal solid wastes (MSW), food wastes from restaurants, households, and food industry waste can be recycled and reused for energy generation.

\subsection{Lignocellulosic Biomass Composition}

Cellulose $\left(\mathrm{C}_{6} \mathrm{H}_{10} \mathrm{O}_{5}\right)_{\mathrm{n}}$, hemicellulose $\left(\mathrm{C}_{5} \mathrm{H}_{10} \mathrm{O}_{5}\right)_{\mathrm{m}}$, and lignin $\left(\mathrm{C}_{10} \mathrm{H}_{11} \mathrm{O}_{3.5}\right)$ are the three major components of lignocellulosic biomass along with small number of other organic compounds such as pectin, protein etc. (Hassan et al., 2018; Bhatia et al., 2018; Bhatia et al., 2019a). The spatial arrangement of these components is dependent on the source of the lignocellulosic biomass and can vary widely. The share of each component as a percentage of the dry matter generally is in the following range: cellulose (30-60\%), hemicellulose (14-40\%) and lignin (7-25\%) (Dahadha et al., 2017). Though, depending on source the composition of these constituents varies as shown in Table 1. The different bond arrangement makes the carbohydrate configuration tough and unyielding to attack.

Cellulose is a linear homopolymer compound that is made up of amorphous and crystalline region. The share of crystalline fraction varies from 50 to $90 \%$. Cellulose is formed by repeated D-glucose sub-units held together by $\beta-1,4$ glycosidic bonds (Kumar and Sharma, 2017). Cellulose exhibits beneficial characteristics e.g. hydrophilicity, biocompatibility, reactive hydroxyl groups and stereoregularity making it an important resource for derivative products such as chemicals, fibers, composites, films, and biofuels (Jedvert and Heinze, 2017). Hemicellulose is a highly branched heteropolymer structure made of pentose ( $\alpha$-LArabinose and $\beta$-D-xylose), hexose ( $\beta$-D-mannose, $\alpha$-D-galactose and $\beta$-D-glucose) sugars 
and sugar acids ( $\alpha$-D-4-O-methyl-D-glucuronic, $\alpha$-D-galacturonic and $\alpha$-D-glucuronic) with small presence of other sugars like $\alpha-\alpha$-L-fucose and L-rhamnose. As opposed to cellulose, it can be easily broken down into monosaccharides due to non-crystalline nature and low degree of polymerization (usually <200) (Farhat et al., 2017). Lignin, the recalcitrant heteropolymer, is the generic name given to a diverse set of complex three-dimensional cross-linked polymers of aromatic alcohols that provide structural rigidity to vascular plants along with cellulose and hemicellulose. It is formed by different structural units of phenyl propane such as guaiacyl, syringyl, and p-hydroxyphenyl (Zhuang et al., 2016), and are linked to each other by carbon-carbon bonds such as 5-5, $\beta-\beta$ and aryl ether linkages e.g., $\beta$ $\mathrm{O}-4, \alpha-\mathrm{O}-4$, provided that aromatic rings contain methoxyl groups substitutes. Lignin is attached to hemicellulose by covalent bonds creating protection against microbial enzyme action, inhibiting usability of raw lignocellulosic biomass for production of bioethanol.

\subsection{Pretreatment of lignocellulosic biomass}

Multiple factors such as complexity of cell-wall constituents, structural heterogeneity, crystallinity of cellulose, and degree of lignification are responsible for the biomass recalcitrance making it resistant to biological and chemical breakdown. To overcome the recalcitrance of feedstock, pretreatment process becomes a significant step in utilizing lignocellulosic biomass for industrial applications. Throughout the pretreatment process, lignocellulosic biomass witnesses a breakdown in crystallinity of cellulose accompanied by reduced degree of polymerization, degradation of hemicellulose and breakage of lignin sheath, upsetting the recalcitrant structure of lignocellulose (Chen et al., 2017). Pretreatment is highly cost-intensive but critical step to enhance accessibility of enzymes during the saccharification step (Gupta et al., 2016; Srivastava et al., 2019). Pretreatment should also reduce chemical reactive consumption, costs and energy demand and enhance the production of monomers of sugar during hydrolysis (Abraham et al., 2020). 
A variety of lignocellulosic biomass pretreatment techniques have been established and fall under four major categories: physical, chemical, physicochemical, and biological (Hassan et al., 2018; Singh et al., 2018; Tu and Hallett, 2019). The selection of the pretreatment processes is governed by the choice of lignocellulosic biomass used as there is variation in the hemicellulose, cellulose and lignin composition (Dahadha et al., 2017). Various pretreatment methods and their successful implementation are depicted in Table 2. While the focus of pretreatment is to break down lignocellulosic biomass into its components, it is also important to keep in view the resultant toxicity in the residual mass for further saccharification and conversion into usable products. Thus, focus is needed to develop and scale the methods that cause less or no toxicity. ILs have proven to be the greenest option in the chemical pretreatment of lignocellulosic biomass (Table 2). While other processes such as supercritical $\mathrm{CO}_{2}$ explosion and steam explosion can also be considered green, ILs certainly have added advantage through their tailor-made nature in their choice of anion and cation making them usable across multiple sources of biomass feedstock. ILs were also found to enhance the production of end-products in various cases (Mohammadi et al., 2019).

\section{Ionic Liquids}

ILs are considered to be green alternatives to volatile organic solvents, as no hazardous chemicals are formed by their application and $\sim 100 \%$ recovery of the IL used is possible (Brandt-Talbot et al., 2017). These salts are entirely organic in nature constituting both anionic and cationic species and possessing a melting point lower than $100^{\circ} \mathrm{C}$ (Alayoubi et al., 2020). At room temperature most of the ILs stay in liquid state, thus making these solvents easy to work with. ILs possess a modular nature and structural alterations can be introduced to the cation core, anion, or substituents. ILs exhibit interesting attributes such as high thermal stability, wide electrochemical window, and wide liquid regions (Jordan and Gathergood, 2015; Alayoubi et al., 2020). ILs can be tuned by altering the branching and 
length of the alkyl chains which are attached to the cation. ILs can be designed accordingly to perform an impressive part in lignocellulosic biomass breakdown (Mai et al., 2014). These unusual characteristics have positioned them as favorable solvents for a variety of applications in environmental chemistry, medicine and nanotechnology. The ability to recycle and reuse ILs further improves the economic efficiency of their application.

\subsection{Chemistry of Ionic liquids}

ILs possess some internal characteristics such as non-flammability, very low vapor pressure, high viscosity, low conductivity, and high thermal and chemical stability (Bhatia et al., 2019a; Paul et al., 2020). These ILs are non-corrosive, economical, have good biodegradability and non-toxic. But few ILs having structures similar to ionic surfactants on releasing into the environment pose the problem of toxicity (Singh et al., 2018; Bhatia et al., 2019b). Several studies have been performed by the researchers focusing on the preparation of ILs using variety of anions and cations and their ability to pretreat lignocellulose under different conditions. The activity of ILs like 1-butyl-3-methylimidazolium chloride $[\mathrm{Bmim}][\mathrm{Cl}], \quad 1$ allyl-3-methylimidazolium acetate $[$ Amim $][\mathrm{OAc}]$ and 1-butyl-3methylimidazolium hydrogen sulphate $[\mathrm{Bmim}]\left[\mathrm{HSO}_{4}\right]$ for saccharification of Norway spruce enzymatically was observed and $[\mathrm{Bmim}]\left[\mathrm{HSO}_{4}\right]$ dissolved lignin most effectively in high water content. Muhammad et al. (2013) performed a comparison of four nitrile constituting ILs like $\left[\mathrm{C}_{2} \mathrm{CNAim}\right][\mathrm{Cl}],\left[\mathrm{C}_{2} \mathrm{CNBim}\right][\mathrm{Cl}],\left[\mathrm{C}_{2} \mathrm{CNHEim}\right][\mathrm{Cl}]$ and 1-propyronitrile-3 benzyl imidazolium chloride $\left[\mathrm{C}_{2} \mathrm{CNBzim}\right][\mathrm{Cl}]$ for extraction of lignin from bamboo at a temperature of $120^{\circ} \mathrm{C}$ for $24 \mathrm{~h}$. Maximum lignin extraction efficiency was observed with [ $\left.\mathrm{C}_{2} \mathrm{CNAim}\right][\mathrm{Cl}]$. Acetate and chloride based ILs with methanol as anti-solvent were used for lignin extraction from Eucalyptus globulus and Pinus radiata from $140^{\circ} \mathrm{C}$ to $170^{\circ} \mathrm{C}$ for $1 \mathrm{~h}$ under microwave heating (Casas et al., 2012). Li et al. (2016) observed the use of 1-Butyl-3methylimidazolium acetate $[\mathrm{Bmim}][\mathrm{OAc}]$ for pretreatment of Eucalyptus followed by $\mathrm{NaOH}$ 
resulted in separation of lignin and glucose production to $90.53 \%$. It may be attributed to the release of better accessibility of IL to reactive surface area in the biomass feedstock.

\subsection{Ionic Liquids in pretreatment of lignocellulosic biomass}

ILs have strong hydrogen bonding coordination making them unique in their ability to dissolve the complete biomass rather than individual subcomponents (Bhatia et al., 2019a), or selectively dissolve components that may not be soluble in conventional solvents, while maintaining the biopolymers intact. Other biomaterials also have been observed to dissolve in ILs, for example lignin from lignocelluloses (Carrozza et al., 2019). The cations in ILs are generally organic e.g. imidazolium $\left(\left[\left(\mathrm{C}_{3} \mathrm{~N}_{2}\right) \mathrm{X}_{\mathrm{n}}\right]^{+}\right)$, ammonium-based $\left[\mathrm{NX}_{4}\right]^{+}$, pyrrolidinium based $\left(\left[\mathrm{C}_{4} \mathrm{~N}\right) \mathrm{X}_{\mathrm{n}}\right]^{+}$, pyridinium $\left(\left[\left(\mathrm{C}_{5} \mathrm{~N}\right) \mathrm{X}_{\mathrm{n}}\right]^{+}\right)$, sulfonium-based $\left[\mathrm{SO}_{3}\right]^{+}$, phosphonium-based $\left[\mathrm{PX}_{4}\right]^{+}$, and few more such as choline, while the anions can be both inorganic and organic (Yoo et al., 2017). Although, all aforementioned variety of ILs have been used, most attention has been given to imidazolium-based ILs (Zhang et al., 2017). Dissolution of cellulose and lignin during the pretreatment process is impacted by both anions and cations.

\subsubsection{Mechanism of dissolution of biomass}

An eventual realization of a predictive tool to recognize new combinations of anions and cations can provide significant breakthroughs in every aspect of the IL pretreatment or sugar production process. Mechanism through which ILs interact with biomass is based on the specific combination of anions and cations along with specific constituent of biomass (hemicelluloses, lignin and cellulose) of interest. Lignocellulosic biomass structure is formed by a mix of seven bond types viz. $\alpha-\mathrm{O}-4, \beta-\mathrm{O}-4, \beta-1, \beta-\beta, \beta-5,5-5$ and $4-\mathrm{O}-5$ of which $\beta-\mathrm{O}-4$ forms the majority $(\sim 50 \%)$. The splitting of $\beta-\mathrm{O}-4$ bond results during pretreatment of biomass, is followed by formation of ion-dipole bonds resulting in the breakdown of lignin structure (Zhang et al., 2019). The splitting of inter-unit bonds diminishes crystallinity and heightens porosity. Several semi-empirical and empirical parameters such as Hansen 
parameters for solubility, COSMO-RS and the Kamlet-Taft parameters for polarity have been used to explain and simulate the solubility of biomass and other biomolecules in ILs. These parameters have served as a good measure to understand the interaction between biomass and ILs resulting in their solubility (Li et al., 2015). Theoretical lignin recovery ability of any IL may be calculated via solvation parameters such as hydrogen bond acidity $(\alpha)$, polarizability $\left(\pi^{*}\right)$ and hydrogen bond basicity $(\beta)$. Muhammad et al. (2011) concluded that extent of biomass deconstruction is directly proportional to hydrogen bond basicity of aromatic cations and anions constituents of ILs. Higher hydrogen bonding basicity $(\beta=1)$ of 1-ethyl-3methylimidazolium glycine $[$ Emim] $]$ Gly] rendered it a better solvent for precipitation of lignin when compared with 1-Ethyl-3-methylimidazolium trifluoroacetate [Emim][TFA]. This is because of weaker electron withdrawing capability of $\mathrm{NH}_{2}$ group present in [Emim][TFA] restricting its effect on biomass deconstruction. Observing the solubility of cellulose and lignin in various ILs as a function of the Kamlet-Taft Basicity ( $\beta$ ) value of the IL reveals that higher $\beta$ value is an indirect measure of their solubility (Fig. 1). The data is mined from various research works conducted (Table 3). Although the maximum solubility is a function of operating parameters such as temperature, dosing, residence time, degree of polymerisation, water content, it is apparent that higher $\beta$ value $(>0.8)$ is important for better solubilization/yield (Minnick et al., 2016; Tomimatsu et al., 2019).

\subsubsection{Dissolution Mechanism of Cellulose by ILs}

Various studies use the empirical solvatichromic parameters to derive a relationship between ILs and their cellulose dissolving capability (Mao et al., 2016), which may be attributed to the type of anion and its affinity to H-bond. The breakdown of cellulose by [Bmim][Cl] can be attributed to the formation of electron donor-electron acceptor (EDA) complex via the interaction of $\mathrm{O}$ and $\mathrm{H}$ atoms of cellulose-hydroxyl with the IL. Hydrogen atoms act as electron acceptors and cellulose molecules as electron pair donors. Similarly, the anion in IL 
functions as the electron pair donor and cation as the acceptor. Under optimal conditions the proximity of these acceptors and donors results in the EDA complex formation. Computational studies have brought forward the interactions between cellulose construct and anion which clearly demonstrated the destruction of cellulose-cellulose linkages resulting in faster dissolution of cellulose (Rabideau et al., 2014). Raj et al. (2016) observed a strong correlation hydrogen bond accepting behavior of imidazolium based ILs and structural transformation of cellulose by measuring various solvation parameters. They concluded that IL pretreatment increases the porosity of biomass consequently increasing the surface area for subsequent hydrolysis process. This effect is further proven by a study where Torr et al. (2016) used 1-Ethyl-3-methylimidazolium Chloride [Emim][Cl] and 1-Ethyl-3methylimidazolium Acetate $[\mathrm{Emim}][\mathrm{OAc}]$ on pine wood at a temperature of $80-120^{\circ} \mathrm{C}$. They were able to demonstrate that IL pretreatment resulted in higher reactional surface area in the wood sample, along with changes in cellulose and lignin crystallinity. Further elucidation of the impact of H-bonding capability of IL with cellulose was demonstrated by Liu et al. (2016). They selected a combination of 21 anions and 17 cations and used COSMO-RS parameters as an indirect measure to determine their ability to breakdown cellulose. They found that cellulose dissolution to be anion-dependent and excess enthalpy calculations pointed out that H-bonding between cellulose and the IL was the prime force driving this.

\subsubsection{Dissolution Mechanism of Lignin by ILs}

The mechanism of lignin dissolution is attained by cleavage of the H-bonds in lignin and merging the aliphatic chain with aromatic nucleus (Xue et al., 2016). Hart et al. (2015) performed a comparative study on solubility of lignin in $[\text { Emim }]^{+}$with different anions, weak coordinating ions tetrafluoroborate $\left(\left[\mathrm{BF}_{4}\right]^{-} \text {and }\left[\mathrm{N}\left(\mathrm{SO}_{2} \mathrm{CF}_{3}\right)_{2}\right] \text { and coordinating ions ([OAc] }\right]^{-}$ $\left.\left[\mathrm{O}_{2} \mathrm{PCOCH}_{2} \mathrm{CH}_{3}\right)_{2}\right]^{-},\left[\begin{array}{lll}\mathrm{CF}_{3} & \mathrm{CO}_{2}\end{array}\right]^{-},\left[\mathrm{CH}_{3} \mathrm{SO}_{3}\right]^{-}[\mathrm{NCS}]^{-},\left[\begin{array}{ll}\mathrm{CF}_{3} & \mathrm{SO}_{3}\end{array}\right]^{-}$and $\left.\left.\left[\mathrm{SO}_{2} \mathrm{CF}_{3}\right)_{2} \mathrm{~N}\right]^{-}\right)$and observed that the latter dissolved considerable amounts of lignin. Financie et al. (2016) 
reported about [Emim] $\left[\mathrm{O}_{2} \mathrm{P}\left(\mathrm{OCH}_{2} \mathrm{CH}_{3}\right)_{2}\right]$ and Perez-Pimienta et al. (2016) reported about [Emim][OAc] ability to readily dissolve lignin. The authors also compared the lignin solubility in ILs to similar anion trifluoromethanesulfonate $\left[\mathrm{CF}_{3} \mathrm{SO}_{3}\right]^{-}$but with various other cations $\left([\mathrm{Emin}]^{+}, \quad[\mathrm{Bmin}]^{+}, \quad\left[\mathrm{N}^{4448}\right]^{+}\right.$, 1-butyl-2,3-dimethylimidazolium $[\mathrm{Bm} 2 \mathrm{im}]^{+}$, and $\left.[\mathrm{Bpyr}]^{+}\right)$, and observed their lignin dissolution capability in the order: $[\mathrm{Emin}]^{+}>[\mathrm{Bmin}]^{+}>[\mathrm{Bpyr}]^{+}>\left[\mathrm{Bm}_{2} \mathrm{im}\right]^{+}>\left[\mathrm{N}^{4448}\right]^{+} . \quad\left[\mathrm{N}^{4448}\right]^{+}$lacks aromatic structures and $\left[\mathrm{Bm}_{2} \mathrm{im}\right]^{+}$has its $\mathrm{C} 2$ carbon methylated resulting in reduction of lignin solubility, confirming that interactions among the aromatic component of lignin and cations impacts lignin solubility in ILs.

\subsection{Lignocellulosic biomass pretreatment using Imidazolium-based ILs}

Raj et al. (2018) observed the influence of pretreatment on mustard stalk using imidazoliumbased ILs at different operating temperatures subsequently conducting enzymatic hydrolysis. They concluded that ILs that contain acetate ions enhance porosity and specific surface area accessible to enzymes thus significantly improving the output of reducing sugar. At $130^{\circ} \mathrm{C} / 2 \mathrm{~h}$, the analysis of differential scanning calorimetry exhibited an increased porosity of $108.9 \mathrm{mg} / \mathrm{g}$ as opposed to a porosity of $107.8 \mathrm{mg} / \mathrm{g}$ at $100^{\circ} \mathrm{C} / 5 \mathrm{~h}$ which on subsequent hydrolysis resulted in production of $97.7 \%$ and $78.7 \%$ glucose. Stanton et al. (2018) also investigated the impact of various imidazolium-based ILs on the properties and structure of biocomposite films blended with silk, and concluded that the anion structure of the ILs affect the intermolecular interactions in the films. Smuga-Kogut et al. (2017) leveraged response surface methodology to study the impact of $[\mathrm{Emim}][\mathrm{Cl}]$ pretreatment on rye straw under operating conditions of $2 \mathrm{~h}, 120^{\circ} \mathrm{C}$ and $1 \mathrm{ml} / \mathrm{g}$ of dry matter rye. They found that enzymatic hydrolysis of pre-treated rye straw yielded almost three times reducing sugars when compared with untreated rye straw. Li et al. (2018) studied the factors affecting biomass dissolution in ILs and found that source of feedstock, anions, cations, temperature, and time 
are key parameters that impact solubility. A significant effort has been underway to study the usage of ILs in dissolution of lignocellulosic biomasses e.g. wheat straw (Lavarda et al., 2019), bagasse (Vieiraa et al., 2019), and corn stover (Papa et al., 2017) have gained traction. Table 3 gives an overview of solubility of lignocellulosic biomass in ILs/co-solvent mixtures. It has been established that higher anion density coupled with the existence of electronaffinity groups in the alkyl chains of IL cation enhances disintegration of lignocellulosic biomass in ILs (Yoo et al., 2017). Further to this, Yavir et al. (2018) suggested that IL cations exhibit $\pi-\pi$ interactions with aromatic compounds of lignin. This observation is further established by the breakdown of lignin obtained with $[\mathrm{Amim}][\mathrm{Cl}]$, which is considered to be an excellent solvent for a variety of woody biomass as it is the only IL that has p-electrons on the side-chain. 1-butyl-3-methylimidazolium chloride $[\mathrm{Bmim}][\mathrm{Cl}]$ and 1 allyl-3methylimidazolium chloride $[\mathrm{Amim}][\mathrm{Cl}]$ can be used to effectively dissolve cellulose at temperatures below $100^{\circ} \mathrm{C}$ (Cai et al., 2014). Under the operating temperature of $50-100^{\circ} \mathrm{C}$, [Amim][Cl] can dissolve up to $10 \%(\mathrm{w} / \mathrm{w})$ concentration of cellulose. The cellulose component of lignocellulosic biomass may be salvaged by the addition of antisolvents such as water, acetone or ethanol to ILs. In fact, crystallinity and digestibility of cellulose are significantly impacted during the regeneration of ILs. Fig. 2 gives an overview of treatment of lignocellulosic biomass using ILs and subsequent regeneration of ILs. Cellulose, recovered using this method, has reduced crystallinity and improved porosity while maintaining same degree of polymerization as untreated cellulose. This makes pre-treated cellulose susceptible to degradation by cellulose, significantly improving glucose output. Microcrystalline cellulose $(\mathrm{MCC})$ can be regenerated using $[\mathrm{Bmim}][\mathrm{Cl}]$. Within 4 hours of regeneration, more than $90 \%$ of the MCC recovered using water and acetone, can be converted into glucose. The conversion ratio stands at $90 \%$ after $40 \mathrm{~h}$ for MCC regenerated from water and freeze dried, 
whereas it is $48.5 \%$ after $96 \mathrm{~h}$ (Cao et al., 2014). ILs can be recovered and reused after each cycle using various methods such as reverse osmosis, ion exchange or salting out.

Hossain et al., 2019 exposed woody biomass (pine wood) to several ILs to extract lignin under various conditions. [Emim][OAc] was able to segregate lignin from woody biomass when pretreated for 18 hours at $115^{\circ} \mathrm{C}$. The lignin thus recovered after pretreatment using ILs is depolymerized and contains the highest molecular mass molecules without forming any new condensed structures. Pretreatment using [Emim] $[\mathrm{OAc}]$ is a better choice over $[\mathrm{Bmim}][\mathrm{Cl}]$, for enhanced enzymatic delignification of woody biomass, possibly because of compatibility with enzymes and its capability to dissolve wood. Application of $\mathrm{N}$ methylpyrrolidinium-2-one chloride $\quad[\mathrm{Hnmp}][\mathrm{Cl}]$ and $\mathrm{N}$-methyl-2-pyrrolidonium methylsulfonate $[\mathrm{Hnmp}]\left[\mathrm{CH}_{3} \mathrm{SO}_{3}\right] \mathrm{ILs}$ on maize stalks at a temperature of $90^{\circ} \mathrm{C}$ for $30 \mathrm{~min}$, resulted in a peak lignin recovery of $85.94 \%$ (Ma et al., 2016). Hamada et al. (2013) used temperature variance to selectively fractionate lignocellulosic biomass into its components. Usage of Pyrolidin-1-ium 2,6-diaminohexanoate [P1ME][Lys] proved to be a good lignin solvent at a temperature below $60^{\circ} \mathrm{C}$, while temperatures above $80^{\circ} \mathrm{C}$ resulted in cellulose solubility. They further found that the lignin yield remained the same even after recycling and reusing the IL for five times.

\subsection{Lignocellulosic biomass pretreatment using non-Imidazolium-based ILs}

Recently there has been progress on the usage of ILs apart from Imidazolium based ones for effectively treating lignocellulosic biomass. When compared to imidazolium-based ILs, cholinium based ones are found to be greener and more economical because their source is natural and renewable (Hou et al. 2012). When compared with untreated bagasse powder, choline acetate $(\mathrm{ChOAc})$ pre-treated bagasse powder produces better propionylated bagasse composites with improved modulus of elasticity from 2.0 giga pascal (GPa) to 2.6 GPa and increased tensile strength from 35 Mega Pascal (MPa) to $40 \mathrm{MPa}$ (Ninomiya et al., 2017). 
Corn stalk when treated with a range of pyrrolidonium-based ILs at $90^{\circ} \mathrm{C}$ for 30 minutes, was witnessed to undergo $85.94 \%$ lignin removal and subsequent enzymatic hydrolysis yielded 91.81\% reducing sugar (Ma et al., 2016). Sun et al. (2014) compared the sugar yields post pretreatment of switchgrass with imidazolium-based and amino acid-based ILs and found the latter to produce better yield of glucose and xylose $(96.5$ and $95.7 \%$ as opposed to 95.8 and $93.3 \%)$.

\subsection{Enhanced enzymatic hydrolysis of lignocellulosic biomass in ILs}

Typically, the enzymes associated with the successful saccharification of cellulose into reducing sugars are endo-1,4- $\beta$ - glucanases, exo-1,4- $\beta$ - glucanases, cellobiases, cellobiohydrolase, and $\beta$-glucosidases. Though ILs are categorized as 'green solvents', they still pose toxicity towards microorganisms. The enzymes get denatured due to the strong hydrogen bonds formed by anions. The selection of IL for pretreatment of biomass should be considered in synergism with the IL biocompatibility with the enzymes. Moreover, ILs are highly viscous which poses an unfavorable effect on the in-situ biocatalytic transformations. Thus, ILs possessing both enzyme compatibility and cellulose dissolving ability are more studied for research purposes in order to conduct one-step hydrolysis of biomass with enzymes in the presence of the solvent ILs. This is important in order to decrease the cost associated with the IL based pretreatment of biomass and converting them into useful products like bioethanol. Kassaye et al. (2017) examined the acidic hydrolysis of bamboo biomass pretreated in alkaline medium followed by treatment with $[\mathrm{Bmim}][\mathrm{Cl}]$. They found that lignin recovery improved with the concentration of sodium hydroxide while biomass recovery reduced owing to the partial loss of lignin and hemicellulose. Moreover, $[\mathrm{Bmim}][\mathrm{Cl}]$ reduced the recalcitrance of bamboo making it more susceptible to further acidic hydrolysis. Alkaline treatment alone increased the yield of total reducing sugars to $64 \%$ as opposed to only $30 \%$ for untreated bamboo sample. Further pre-treatment with IL, increased 
the yield of reducing sugar to $80 \%$. Tiong et al. (2017) performed hydrolysis of cellulose (oil palm) at $160{ }^{\circ} \mathrm{C}$ for $5 \mathrm{~h}$ post pretreatment with Bronsted Lewis acidic IL resulting in the formation of glucose. Further dehydration of the glucose results in the formation of 5Hydroxymethylfurfural (5-HMF). They also observed that higher IL loading resulted in decrease in 5-HMF production, which may be attributed to 5-HMF's high instability and its ease of condensation.

Nargotra et al. (2018) found that alkali $(\mathrm{NaOH})$ pretreatment combined with IL [Bmim] $[\mathrm{Cl}]$ resulted in $69.14 \%$ increase in reducing sugar yield from sunflower stalk with a saccharification efficiency of $26.51 \%$. Ma et al. (2016) pretreated corn stalk pretreated with $[\mathrm{Hnmp}] \mathrm{Cl}$ and $[\mathrm{Hnmp}] \mathrm{CH}_{3} \mathrm{SO}_{3}$ at $90{ }^{\circ} \mathrm{C}$ for 30 minutes achieving a lignin recovery of $85.94 \%$ and $56.02 \%$ respectively. This resulted in the production of $91.81 \%$ and $73.59 \%$ of reducing sugar respectively post enzymatic hydrolysis. Hou et al. (2012) conducted a similar experiment on rice straw for lignin removal using Cholinium lysine [Ch][Lys] and found the maximum yield of glucose $(87.7 \%)$ was obtained when the biomass was pre-treated at $90^{\circ} \mathrm{C}$ for 24 hours, while further increasing the temperature actually reduces the output. Hashmi et al. (2017), studied the effect of 1-butyl-3-methylimidazolium acetate [Bmim][OAc] on autohydrolysis of sugarcane bagasse. Their study found that pretreatment using [Bmim] $[\mathrm{OAc}]$ at $110^{\circ} \mathrm{C}$ for 30 minutes caused a significant reduction in the amount of present lignin and crystallinity of cellulose and improved the digestibility of xylan and glucan (98.6\% and $97.4 \%$ respectively). Xylan and glucan exhibited enhanced autohydrolysis rate of $57.5 \%$ and $62.1 \%$ respectively at $205^{\circ} \mathrm{C}$. Rigual et al. (2017) studied the effect of microwave IL $[$ Emim] $[\mathrm{OAc}]$ and autohydrolysis pretreatment on Eucalyptus followed by enzymatic hydrolysis. Autohydrolysis enhanced the enzymatic digestibility in eucalyptus and microwave IL enhanced the lignin removal resulting in better recovery of cellulose. The highest glucan digestibilities of 84.4 and $85.5 \%$ were obtained for autohydrolysis at $175^{\circ} \mathrm{C}$, 
IL pretreatment at $80^{\circ} \mathrm{C}$, and autohydrolysis at $175^{\circ} \mathrm{C}$, IL pretreatment at $120^{\circ} \mathrm{C}$ respectively. The autohydrolysis at $175^{\circ} \mathrm{C}, \mathrm{IL}$ pretreatment at $120^{\circ} \mathrm{C}$ resulted in maximum glucan output of $39.6 \mathrm{~g} / 100 \mathrm{~g}$ of untreated wood. ILs along with solid phase acid catalysts can be used for cellulose hydrolysis. Xiong et al. (2014) studied hydrolysis of cellulose using [Bmim][Cl] as the IL and $\mathrm{Fe}_{3} \mathrm{O}_{4} @ \mathrm{SiO}_{2}-\mathrm{SO}_{3} \mathrm{H}$ acid catalyst for hydrolysis. They treated Avicel ${ }^{\circledR}$ cellulose for $8 \mathrm{~h}$ at $130^{\circ} \mathrm{C}$ and found a fair yield of $73 \%$ of reducing sugars. An important point to note is the reusability of the catalyst $\mathrm{Fe}_{3} \mathrm{O}_{4} @ \mathrm{SiO}_{2}-\mathrm{SO}_{3} \mathrm{H}$ due to easy recovery from reaction mixtures using a permanent magnet, and high stability during the hydrolysis without any noticeable loss in activity. Zhang et al. (2015) used various ILs with acid catalysts under microwave radiation to study their impact on the hydrolysis of straw. They found the combination of $[\mathrm{Bmim}][\mathrm{Cl}]$ with $\mathrm{H}_{2} \mathrm{SO}_{4}$ at $150^{\circ} \mathrm{C}$ under microwave heating to yield the maximum amount of reducing sugar $35.5 \mathrm{wt} \%$ upon hydrolysis as opposed to $19.8 \mathrm{wt} \%$ when using water as a solvent and conventional heating.

\subsection{Enhanced bioconversion of lignocellulosic biomass using ILs}

ILs based pretreatment can increase enzymatic digestibility and biofuel yield. Saha et al. (2018) used [Emim][OAc] to pretreat sugarcane bagasse for $2 \mathrm{~h}$ at $140^{\circ} \mathrm{C}$ and use X-Ray diffraction and SEM to study the structure of resultant biomass. They observed a reduction in the crystallinity index by $14.7 \%$ resulting in enhanced bioconversion of pretreated bagasse into reducing sugars. Mohammadi et al. (2019), pre-treated spruce (softwood) and birch (hardwood) with IL 1-H-3-methylmorpholinium chloride [HMMorph][Cl]. The subsequent hydrolysis under optimum conditions of $140^{\circ} \mathrm{C}$ for $3 \mathrm{~h}$ yielded more than 3.3 times output than the untreated substrate. Ethanol production, via fermentation of the resultant hydrolysates, increased by more than $34.8 \%$. Yang et al. (2016) performed a study using three different ILs $[\mathrm{Amim}][\mathrm{Cl}],[\mathrm{Bmim}][\mathrm{Cl}]$ and 1-Ethyl-3-methylimidazolium chloride $[$ Emim $][\mathrm{Cl}]$ on triploid poplar under the reaction conditions of $130^{\circ} \mathrm{C}$ for $2 \mathrm{~h}$ followed by 
enzymatic hydrolysis at $50^{\circ} \mathrm{C}$ for $48 \mathrm{~h}$. They observed the conversion of cellulose I to cellulose II which inherently resulted in 1.3 times yield of fermentable sugars, thereby resulting in enhance production of bioethanol from biomass.

\section{Commercialization of IL based pretreatment on lignocellulosic biomass}

For efficient utilization of biomass, it is important to fractionate the biomass into its constituents via pretreatment process. Inspite of the fact that a lot of research is going on lignocellulosic biomass conversion into biomaterials, the pretreatment process stills holds to be very expensive presenting $11-27 \%$ of the total costs (Madanayake et al., 2017). The method involving pretreatment generally have elevated costs, long reaction time, higher consumption of energy, lower degradation of sugar, environmental pollution and high requirement for corrosion resistance of the equipment. Pretreatment process depends on various factors (a) value of the by-products (b) kind of biomass. To ensure the efficiency and economic viability of the pretreatment process, it should have following characteristics: (a)

lower concentration of fermentation step inhibitors (b) higher yields of sugar from fermentation (c) hemicellulose and lignin recovery for production of valuable by-products (iv) minimal energy, water and chemicals (Mussatto and Bikaki, 2016).

\subsection{Modeling and simulation of large-scale pretreatment process using ILs}

Developing an efficient design of processing units and optimizing the process parameters are the criterion for large scale pretreatment of lignocellulosic biomass using ILs. Baral and Shah (2016) proposed a full-scale pretreatment plant for pretreatment of biomass using Super Pro Designer software. The model operates with a comprehensive process design involving feedstock grinding and milling, pretreatment of biomass, enzymatic hydrolysis and recovery of ILs. Though, it lacked the logistics behind the feedstock. Oleskowicz-Popiel et al. (2014) also developed a plant for IL-mediated pretreatment of lignocellulosic biomass into ethanol by Super Pro Designer. The same software was used to develop a model including various 
parameters such as reactor design and energy intensity of IL by Parthasarathi et al. (2016). A reduction in $75 \%$ of the pretreatment energy cost was observed through this model implementation. Brandt-Talbot et al. (2017) observed the fractionation of Miscanthus using triethylammonium hydrogen sulphate $\left(\left[\mathrm{Et}_{3} \mathrm{NH}\right]\left[\mathrm{HSO}_{4}\right]\right)$ and also explored the economic routes for fractionation of IonoSolv. Delignification of $85 \%, 80 \%$ recovery of lignin and $80 \%$ yield of glucose was obtained in this process. They further reported that increase in the recycling rate of IL unusually decreases the high cost of glucose production which in turn results in an economically viable process. Sen et al. (2012) established a process model for pretreatment of corn stover using ILs resulting in the production of sugar. Their modelling studies were based on experiments and simulated moving bed separation technique. They designed the decrystallization unit having the first hydrolysis for $150 \mathrm{mins}$ and second hydrolysis for 180 mins. 98\% recovery of IL was obtained by simulated moving bed separation technology. To reduce the consumption of IL, authors recommended hydrolysis by dilute acid first and subsequently followed by IL. In 2017, the process parameters were optimized by Gogoi and Hazarika for lignin recovery from IL-pretreated lignocellulosic biomass using nanofiltration membranes. Anugwom et al. (2016) derived a mathematical model for three different reactors used in dissolution of lignin by alkanol amine based switchable ILs. They further analyzed and optimized the model by Modest ${ }^{\mathrm{TM}}$ software and observed that rotating bed reactor was an efficient reactor with respect to dissolution of lignin on comparing to loop reactor and non-stirring batch reactor. However, these computer-based models should be more developed with respect to solid loading, quantity of feedstock supply, agitation level and heat and mass transfer.

\subsection{Cost Analysis of IL based pretreatment}

ILs are costly solvents, which is detrimental to their large-scale application in industry. Thus, their recycle and reuse in biomass pretreatment can be an effective tool to reduce cost 
coverage (Perez-pimienta et al., 2016). Various recycling methods have been developed and studied at laboratory scale (Mai et al., 2014). Hou et al. (2012) conducted a study on the regeneration and reapplication of eight ILs concocted using amino acids anions and cholinium cation ([Ch][AA]). They concluded that repeated use of recycled IL (five times) resulted in a marginal reduction in lignin recovery from $58.8 \%$ to $52.5 \%$. While IL reuse definitely reduces the overall processing cost, it was observed that recycling of [Bmim] $[\mathrm{OAc}]$ and $[\mathrm{Amim}][\mathrm{Cl}]$ slightly decreases the digestibility of cellulose (Xu et al., 2017).

A cost-revenue analysis was performed by Sen et al. (2012) for a 10 tonne/hour biomass pretreatment plant. They were able to create a model that could bring down total cost (operational, setup and fixed costs) to achieve mean selling price of $\$ 1.14 / \mathrm{kg}$ of sugar. This process accounted for reusability of ILs with 95-99\% recovery, multi-step hydrolysis with first step being dilute acid hydrolysis followed by IL-based hydrolysis. Their model accounted for Capex (setup cost) and Opex (feed material, upkeep and waste removal cost). Total plant cost $C_{\text {Total }}$ can be calculated as:

$$
C_{\text {Total }}=C_{\text {Capex }}+C_{\text {Opex }}
$$

A model developed by Wright and Brown, (2007) to calculate the optimal cost of biorefineries established the following equations to estimate cost of a large-scale IL based pretreatment plant.

$$
\begin{gathered}
C_{\text {Capex }}=C_{o}\left(M / M_{o}\right)^{a} \\
C_{\text {Opex }}=C_{o}\left(M / M_{o}\right)^{a}+C_{P}+C_{F}+C_{D}=C_{P o}\left(M / M_{o}\right)^{b}+C_{D o}\left(M / M_{o}\right)^{c}+C_{F o}\left(M / M_{o}\right)
\end{gathered}
$$

Here, $C_{P}$ is total operational cost of the plant, $C_{F}$ is the cost price of biomass produced at farm, $C_{D}$ is the cost of biomass delivery, $M$ is the installed capacity of the plant, $M_{o}$ is the capacity of base plant, and o subscripted cost components are costs at capacity $M_{o}$. The range of values for dimensionless scale factors $\mathrm{a}, \mathrm{b}$ and $\mathrm{c}$ are taken as $0.6-0.8,0.9-1$ and 1.5, respectively. 
Konda et al. (2014) established a simulative functional model for a one-pot biofuel production from IL pretreated biomass and were able to achieve a competitively low production cost of $\$ 3 /$ gallon. They were able to achieve this by lignin valorization and few other advancements. They took into account the operational costs of production such as raw material, power and infrastructure. Another model developed by Baral and Shah (2016) for a commercial-scale study using SuperPro Designer software brought forward the technoeconomic practicability of IL pre-treatment. They utilized poplar, corn stover and switchgrass as feedstock for a 113 million liter/year plant for the base case. The key process parameters observed during their feasibility study were recovery of IL, its cost, and heat recovery. Total investment costs (including initial setup cost, total fixed costs, and working capital) for corn stover, switchgrass and poplar were evaluated to be $\$ 873, \$ 1002$ and $\$ 941 / \mathrm{t}$ of total sugars respectively. Baral and Shah (2017) also stated that the total cost of biofuel production via fermentation of lignocellulosic biomass could be reduced by wastewater management in the process. Fermentable sugars are the main constituent of wastewaters from biorefineries with 74.1-79.0 wt \% lignin in the biomass. Lignin can be utilized for producing high value products like biochar, bio-oil and biogas production. Klein-Marcuschamer et al. (2011) validated that IL cost, IL recovery and IL loading have direct impact on the minimum selling price of ethanol. They also found that sale of residual lignin combined with the reduction in cost of IL can bring down the net selling price of ethanol to \$1.50/gallon. Settani et al. (2016) suggested that focus should be shifted from effective recycling to usage of inexpensive ILs synthesized from cheap raw materials in order to make their usage cost-efficient. They demonstrated that production cost of 1-methylmidazole hydrogen sulfate $\left([\mathrm{Mmim}]\left[\mathrm{HSO}_{4}\right]\right)$ and $\left[\mathrm{Et}_{3} \mathrm{NH}\right]\left[\mathrm{HSO}_{4}\right]$ can hit a competitive price of $\$ 2.96-5.88 / \mathrm{kg}$ and $\$ 1.24 / \mathrm{kg}$ respectively, which is comparable to the prices of organic solvents. But their commercial application in pretreatment plants will need some more analysis of their delignification performance. 
As most applications of ILs in biomass pretreatment have been limited to laboratory scale, there is a need for further research to make application of ILs commercially viable. Nonetheless, there is a need for further commercial scale studies keeping in mind various operational parameters to create a low-cost methodology utilizing ILs for the pretreatment process to accelerate industrial-scale adoption.

\section{Advantages and drawbacks of ILs based pre-treatment}

The green nature of ILs makes them an excellent choice in the pretreatment process when compared to more hazardous chemicals that are currently in use while maintaining comparable sugar yields. Brandt-Talbot et al. (2017) pioneered the use of Triethylammonium hydrogen sulfate $\left[\mathrm{N}_{2220}\right]\left[\mathrm{HSO}_{4}\right]$, a low-cost IL for pre-treating Miscanthus x giganteus grass. This IL exhibited solubilization levels of up to $100 \%$ hemicellulose and $75 \%$ lignin. Further enzymatic saccharification yielded around $77 \%$ glucose. This IL was also reused with $99 \%$ recovery for four times. Despite of their unique chemical properties and greenness, usage of ILs in pretreatment of lignocellulosic biomass present certain shortcomings - (i) the recovery and reuse of ILs is challenging, (ii) usage of ILs is cost-intensive despite some progress in making it cheaper, (iii) post-cellulose extraction the recovery of hemicellulose and lignin from the ILs poses some difficulty (iv) they may be toxic to microorganisms and enzymes. The solutions become viscous and tough to handle post cellulose extraction making it difficult to recover hemicellulose and lignin. Usage of water-ILs mixture can be a solution to avoid this problem. Some ILs can cause an irreversible inactivation of enzymes impacting the cellulase activity negatively (Pedersen et al., 2019). Thus, to enhance the sugar yields and preserve cellulase activity, removal of IL residues precedes enzymatic hydrolysis.

\subsection{Toxicity and Biodegradability}

From the initial research related to chloride constituting ILs concentrating only on lignocellulosic biomass pretreatment, the focus shifted towards ILs with lower toxicities. Mai 
et al. (2014) used [Emim][DMP]-DMSO (1:1) and [Emim][OAc]-DMA (1:1) in their study as IL formulations for rice straw for cellulose dissolution. Generally, ILs constituting chlorides pose toxicity and have corrosive properties, which might not be suitable to be used in biorefinery projects. Researchers are now promoting the use of biological agents, which are exposed to ILs during biocatalytic conversions or fermentation. In such cases, ILs can act as a media for microbial processes. ILs biocompatibility is a crucial factor to counterbalance the complex processes and surplus cost of efficient purification of biomass for further microbiological processes. Non-toxic ILs opens more opportunities for enhancing the applications of ILs for eg. the use of food grade chemicals. Concerns related to impacts of residual quantities of impurities produced from IL synthesis (Francesco et al., 2017) were also observed. This would involve huge costs for purification procedures.

ILs exhibiting biodegradability properties are preferred for lignocellulosic biomass dissolution to promote the use of environmentally sustainable ILs and to live up to their role of 'green solvents'. Hou et al. (2012) reported that cholinium constituting ILs possess low toxicity and are readily biodegradable. ILs generation from renewable materials along with its biodegradability are essential factors with respect to biorefinery model. Hou et al. (2013) prepared several ILs like choline glycine, choline alanine and choline lysine for pretreatment of sugarcane bagasse. Choline lysine showed the best results yielding $84 \%$ xylose and $80 \%$ glucose from enzymatic hydrolysis of the residue.

\subsection{Recyclability and Recovery of ILs}

Recycling property of ILs is enabled due to their near-zero volatility under ambient conditions. As ILs are considered to be as expensive solvents, it is important to recover ILs after extraction of cellulose and lignin in order to develop an economical and energy saving protocol (Zhang et al., 2017; Hossain et al., 2019). The solution comprises of acetone, lignin, IL and water after extraction of cellulose. Evaporation of acetone followed by lignin 
precipitation, leaves behind IL in aqueous solution. Evaporation of water using a rotary evaporator under reduced pressure, recovers the ILs. The ILs after recovery are vacuum dried at a temperature of $80^{\circ} \mathrm{C}$. This process can lead to $90 \%$ recovery of IL. The ILs, constituting dimethylamine with $\mathrm{CO}_{2}$ in the ratio $2: 1$ to produce dimethyl carbamate anion and dimethylammonium cation are distillable at low temperatures of $45^{\circ} \mathrm{C}$ thus enhancing the options for applications and IL recycling. Hou et al. (2013) demonstrated the recovery and reuse of $50 \%[\mathrm{Ch}][\mathrm{Lys}]-$ water mixture directly (without lignin filtration) in bagasse pretreatment for three batches. However, due to repeated use of ILs, the yields of xylose and glucose decreased to $73.0 \%$ and $62.7 \%$ respectively. It may be due to reduction in delignification capacity of the solvent mixture owing to amassing lignin. In a study performed by Brandt-Talbot et al., (2017), triethylammonium hydrogen sulfate (an economic IL), was used for pretreatment of Miscanthus x giganteus grass. They observed 100\% dissolution of hemicellulose and 75\% lignin solubilization using the IL solution. They reused the same IL four times obtaining a recovery of $99 \%$ at each time. Thus, IL recovery is an integral part of lignocellulosic biomass pretreatment process. This way the integrity of IL can be preserved by a fairly simple regeneration process.

\subsection{SWOT Analysis}

\subsubsection{Strengths}

Their unusual physico-chemical properties such as high thermal stability, melting point, and low vapor pressure are an asset for dissolution of biomass. ILs also possess high selectivity homogeneous phase derivatization. ILs have high extraction properties and binary mixtures (IL+ organic solvents) can be applied to the mixture for better extraction. ILs have proven to be very beneficial in extraction of food additives, cosmetics and nutraceuticals. Dissolution extraction selectivity and capacity can be adjusted by the structural design of the ILs. The advantages of completely liquefying the biomass as one of the first steps in a biorefinery may 
lie in a lower waste fraction, a reduction in the number of required processing steps, a higher selectivity, lower energy demand, or greater flexibility in feed variety for the IL-based dissolution compared to heterogeneous processes.

\subsubsection{Weaknesses}

ILs are quite expensive with little information on cradle to grave life cycle assessment. Side reactions or strong adsorption on polar surfaces leads to loss in ILs. ILs are viscous solvents which in turn affects the processing costs. Conventional recovery and purification steps of ILs are also costly. ILs are composed of ions on and hence feature a low vapour pressure. Therefore, distillation is not in general an adequate means of removing impurities from ILs (as is conventionally done for the purification of organic solvents). Furthermore, their high dissolution capacity for polar molecules, an advantage for homogenizing biomass, can also turn into a disadvantage, as many polar compounds, such as water, inorganic salts, acids, monosaccharides and their decomposition products, accumulate and in turn affect the properties. It is difficult to remove moisture from ILs due to absorption of moisture from the feed and drying of ILs is time and energy consuming. There is a lack of data for specific ILs, including chemical engineering data on biorefinery-relevant mixtures of ILs and bio-based chemicals (required for modelling purposes), material compatibility, occupational safety and health (HSE), biodegradability and toxicity data.

\subsubsection{Opportunities}

The opportunities for the deployment of IL based pretreatment are immense due to the multitude of benefits that ILs bring forth. Their green nature, recyclability and highly tuneable characteristics being major drivers for their acceptance. While there is plethora of ILs being explored, the real opportunity is replacing conventional solvents with ILs at large scale pretreatment plants. Another key opportunity is the development of bio-based ILs that can be created in the same pretreatment plants from similar feedstock as the ones being used 
in biorefinery. The shift in regulatory norms and drive towards a circular bioeconomy is also a major push for the development of IL based pretreatment technologies.

\subsubsection{Threats}

When comparing ILs against the mainstream solvents and other pretreatment techniques there is little information. In case of large-scale process like biomass fractionation and hydrolysis to fermentable sugars, IL technologies face competition with novel techniques like AFEX, Ultrasound and Microwave processes. Although the most likely approach to integrated biorefineries is to add further feed streams and product streams onto a dedicated biorefinery (e.g. sugar or pulp/paper mill), rather than building an integrated biorefinery from scratch, large investments are required, and the technical as well as bio-based product resilience needs to be overcome. Clearly, the risk currently is very high as no example for an integrated biorefinery, let alone one involving IL processes, is in operation as proof of principle.

\section{Gaps in Knowledge}

Ionic liquids are an efficient means for pretreatment of lignocellulose but still there are certain research gaps which needs to be addressed. Economic production of ILs in volumes, improvement in recyclability regeneration and reactivation of used IL, and identifying applications of used ILs are few gaps which needs to be discussed further. Developing an efficient recycling and reuse technique for handling the large volumes of lignocellulosic biomass. The process of using ILs for lignocellulosic pretreatment also requires integration of the process to reduce the cost and energy requirement. Proper design of the reactors and establishing the scale-up rules for lignocellulosic pre-treatment along with appropriate reaction kinetics and modelling of mass and heat transfers should be studied. Proper studies related to rheology in order to determine distortion in flow of ILs, any changes in thermal, chemical and structural properties during pretreatment of biomass should be promoted to successfully implement its large-scale application. 


\section{$7 \quad$ Future Research Directions}

Most of the studies conducted on lignocellulosic pretreatment using ILs were laboratory scale. Thus, to scale and increase the adoption of this technique there is a need to conduct bench scale and pilot implementations in order to identify and overcome the challenges encountered during commercial use of IL in biomass pretreatment. Establishing reaction kinetics at commercial scale would need bringing together the knowledge attained during lab and bench scale experiments. Although some work has happened on bio-based ILs and their usage, there is a need for further progress to be made in synthesis of low-cost bio-based ILs. Research is needed to understand in detail the combinatory effect of ILs when used with water other co-solvent mixtures for delignification studies. While there is ongoing research on various operating conditions and parameters, viz. temperature, pressure, external stimuli, stirring speed, residence time, further exploration is needed to arrive at repeatable and standard operating conditions. There is a need to create a standard database of various feedstock, their pretreatment using various ILs, parameters used, reactor design and configurations, so that techno-economic assessments can be performed using simulations in ASPEN to build case for pilot deployments. Furthermore, conventional heating using oil bath may be replaced with microwave and ultrasound in IL based pretreatment. Current works have only scratched the surface of applications of IL-biomass interaction, which means that there is untapped potential requiring further exploration of these beneficial salts.

\section{Conclusion}

Utilization of lignocellulosic biomass is a useful way for clean energy generation along with organic wastes reduction. Overcoming the recalcitrance posed by lignocellulosic biomass through pretreatment is vital for any type of biological and chemical treatment to result in the production of biofuels and bioproducts. ILs as dissolution media present a wide array of advantages due to their greenness and customizability. ILs have also been proven to 
significantly impact the output of end products such as xylan, glucan and other reducing sugars. Regardless, their high cost and viscous nature inhibits large-scale adoption and requires further research for effective commercialization.

\section{Acknowledgements}

VKG, MS and RB acknowledge the support under the ongoing project-VALORTECH, which has received funding from the European Union's Horizon 2020 research and innovation program under grant agreement No 810630. Authors acknowledge editing of the manuscript, the language content and grammar to Dr. Urvashi Kuhad, Department of English, University of Delhi, New Delhi. The english quality of paper was also checked by one of the authors, Professor Nicholas Gathergood, who is a native English speaker.

\section{Conflict of Interest}

The authors declare no conflict of interest.

\section{References}

1. Abraham, A., Mathew, A.K., Park, H., Choi, O., Sindhu, R., Parameswaran, B., Pandey, A., Park, J.H., Sanga, B-I., 2020. Pretreatment strategies for enhanced biogas production from lignocellulosic biomass. Bioresour. Technol., 122725.

2. Alayoubi, R., Mehmood, N., Husson, E., Kouzayha, A., Tabcheh, M., Chaveriat, L., Sarazi, C., Gosselin, I., 2020. Low temperature ionic liquid pretreatment of lignocellulosic biomass to enhance bioethanol yield. Renew. Energy, 145, 1808-1816.

3. Alexandropoulou, M., Antonopoulou, G., Fragkou, E., Ntaikou, I., Lyberatos, G., 2017. Fungal Pretreatment of Willow Sawdust and Its Combination with Alkaline Treatment for Enhancing Biogas Production. J. Environ. Manag., 203, 704-713. 
4. Alvarez, A., Cachero, S., Gonzalez-Sanchez, C., Montejo-Bernardo, J., Pizarro, C., Bueno, J.L., 2018. Novel method for holocellulose analysis of non-woody biomass wastes. Carbohydr. Polym., 189, 250-256.

5. Anugwom, I., Rujana, L., Warna, J., Hedenstrom, M., Mikkola, J.P., 2016. In quest for the optimal delignification of lignocellulosic biomass using hydrated, $\mathrm{SO}_{2}$ switched DBU MEASIL switchable ionic liquid. Chem. Eng., J. 297, 256-264.

6. Baral, N.R., Shah, A., 2016. Techno-economic analysis of cellulose dissolving ionic liquid pretreatment of lignocellulosic biomass for fermentable sugars production. Biofuels, Bioprod. Bioref., 10, 70-88.

7. Baral, N.R., Shah, A., 2017. Techno-economic analysis of utilization of stillage from a cellulosic biorefinery. Fuel Process. Technol., 166, 59-68.

8. Bhatia, S.K., Jagtap, S.S., Bedekar, A.A., Bhatia, R.K., Patel, A.K., Pant, D.J., Banu, R., Rao, C.V., Kim, Y-G., Yang, Y-H., 2019a. Recent developments in pretreatment technologies on lignocellulosic biomass: Effect of key parameters, technological improvements, and challenges. Bioresour. Technol., 122724.

9. Bhatia, S.K., Gaurav, R., Choi, T.R., Jung, H.R., Yang, S.Y., Moon, Y.M., Song, H.S., Jeon, J.M., Choi, K.Y., Yang, Y.H. 2019b. Bioconversion of plant biomass hydrolysate into bioplastic (polyhydroxyalkanoates) using Ralstonia eutropha 5119. Bioresour. Technol., 271, 306-315.

10. Bhatia, S.K., Joo, H.S., Yang, Y.H., 2018. Biowaste-to-bioenergy using biological methods - A mini-review. Energy. Convers. Manage., 177, 640-660.

11. Brandt-Talbot, A., Gschwend, F.J., Fennell, P.S., Lammens, T.M., Tan, B., Weale, J., et al., 2017. An economically viable ionic liquid for the fractionation of lignocellulosic biomass. Green Chem., 19, 3078-3102. 
12. Cai, C.M., et al., 2014. Integrated furfural production as a renewable fuel and chemical platform from lignocellulosic biomass, J. Chem. Technol. Biotechnol., 89, 2-10.

13. Cao, X., Peng, X., Sun, S., Zhong, L., Wang, S., Lu, F., Sun, R., 2014. Impact of regeneration process on the crystalline structure and enzymatic hydrolysis of cellulose obtained from ionic liquid. Carbohydr. Polym. 111, 400-403. J. Appl. Polym. Sci. 116, $547-554$

14. Carrozza, C.F., Papa, G., Citterio, A., Simmons, R.S.B.A., Singh, S., 2019. One-pot bioderived ionic liquid conversion followed by hydrogenolysis reaction for biomass valorization: A promising approach affecting the morphology and quality of lignin of switchgrass and poplar. Bioresour. Technol., 294, 122214.

15. Casas, A., Oliet, M., Alonso, M.V., Rodriguez, F., 2012. Dissolution of Pinus radiata and Eucalyptus globulus woods in ionic liquids under microwave radiation: lignin regeneration and characterization. Sep. Purif. Technol., 97, 115-122.

16. Chen, H., Liu, J., Chang, X., Chen, D., Xue, Y., Liu, P., et al., 2017. A review on the pretreatment of lignocellulose for high-value chemicals. Fuel Process. Technol., 160, 196206.

17. Cheng, F., Zhao, X., Hu, Y., 2018. Lignocellulosic biomass delignification using aqueous alcohol solutions with the catalysis of acidic ionic liquids: A comparison study of solvents. Bioresour. Technol., 249, 969-975.

18. Dahadha, S., Amin, Z., Lakeh, B.A.A., Elbeshbishy, E., 2017. Evaluation of different pretreatment processes of lignocellulosic biomass for enhanced biomethane production. Energ. Fuel., 31, 10335-10347.

19. da Silva, A.R.G.A., Giuliano, A., Errico, M. et al., 2019. Economic value and environmental impact analysis of lignocellulosic ethanol production: assessment of different pretreatment processes. Clean Techn. Environ. Policy, 21, 637-654. 
20. de Paula, R.G., Antonieto, A.C.C., Ribeiro, L.F.C., Srivastava, N., Donovan, A.O., Mishra, P.K., Gupta, V.K., Silva, R.N., 2019. Engineered microbial host selection for value-added bioproducts from lignocellulose. Biotechnol. Adv., 37, 107347.

21. Duque, A., Manzanares, P., Ballesteros, M., 2017. Extrusion as a pretreatment for lignocellulosic biomass: Fundamentals and applications. Renew. Energy, 114B, 14271441.

22. Farhat, W., Venditti, R.A., Hubbe, M., Taha, M., Becquart, F., Ayoub, A., 2017. A review of water-resistant hemicellulose-based materials: processing and applications. Chem. Sus. Chem. 10, 305-323.

23. Financie, R., Moniruzzaman, M., Uemura, Y., 2016. Enhanced enzymatic delignification of oil palm biomass with ionic liquid pretreatment. Biochem. Eng. J., 110, 1-7.

24. Francesco, M.D., Simonetti, E., Gorgi, G., Appetecchi, G.B., 2017. About the Purification Route of Ionic Liquid Precursors. Challenges, 8(1), 11.

25. Glas, D., Van Doorslaer, C., Depuydt, D., Liebner, F., Rosenau, T., Binnemans, K., De Vos, D.E., 2014. Lignin solubility in non-imidazolium ionic liquids. J. Chem. Technol. Biotechnol., 90(10), 1821-1826.

26. Gogoi, G., Hazarika, S., 2017. Coupling of ionic liquid treatment and membrane filtration for recovery of lignin from lignocellulosic biomass. Sep. Purif. Technol., 173, 113-120.

27. Gschwend, F. J. V., Brandt, A., Chambon, C. L., Tu, W.-C., Weigand, L., and Hallett, J. P., 2016. Pretreatment of Lignocellulosic Biomass with Low-cost Ionic Liquids. J. Vis. Exp., (114), e54246.

28. Gschwend, F.J.V., Chambon, C.L., Biedka, M., Brandt-Talbot, A., Fennell, P.S., Hallett, J.P., 2019. Quantitative glucose release from softwood after pretreatment with low-cost ionic liquids. Green. Chem. 21, 692-703. 
29. Gupta, V.K., Kubicek, C.P., Berrin, J-G., Wilson, D.W., Couturier, M., Berlin, A., Filho, E.X.F., Ezeji, T., 2016. Fungal Enzymes for Bio-products from Sustainable and Waste Biomass. Trends Biochem Sci., Cell Press, 41, 633-645.

30. Hamada, Y., Yoshida, K., Asai, R., Hayase, S., Nokami, T., Izumi, S., et al., 2013. A possible means of realizing a sacrifice-free three component separation of lignocellulose from wood biomass using an amino acid ionic liquid. Green Chem., 15(7), 1863-1868.

31. Hart, W.E.S., Harper, J.B., Aldous, L., 2015. The effect of changing the components of an ionic liquid upon the solubility of lignin. Green Chem., 17, 214-218.

32. Hashmi, M., Sun, Q., Tao, J., Wells, T., Shah, A. A., Labbe, N., Ragauskas, A.J., 2017. Comparison of autohydrolysis and ionic liquid 1-butyl-3-methylimidazolium acetate pretreatment to enhance enzymatic hydrolysis of sugarcane bagasse. Bioresour. Technol., $224,714-720$.

33. Hassan, S.S., Gwilym, A., Williams, Jaiswal, A.K. 2018. Emerging technologies for the pretreatment of lignocellulosic biomass. Bioresour. Technol., 262, 310-318.

34. Hernandez-Beltran, J.A., Lira, H-D.I.O., Cruz-Santos, M.M., Saucedo-Luevanos, A., Hernandez-Teran, F., Balagurusamy, N., 2019. Insight into Pretreatment Methods of Lignocellulosic Biomass to Increase Biogas Yield: Current State, Challenges, and Opportunities. Appl. Sci., 9, 3721.

35. Hossain, M.M., Rawal, A., Aldous, L., 2019. Aprotic vs protic ionic liquids for lignocellulosic biomass pretreatment: anion effects, enzymatic hydrolysis, solid-state nmr, distillation, and recycle. ACS Sustainable Chem. Eng., 7, 11928-11936.

36. Hou, X.D., Li, N., Zong, M.H., 2013. Facile and simple pretreatment of sugar cane bagasse without size reduction using renewable ionic liquids-water mixtures. ACS Sustainable Chem. Eng., 1(5), 519-526. 
37. Hou, X.D., Smith, T.J., Li, N., Zong, M.H., 2012. Novel renewable ionic liquids as highly effective solvents for pretreatment of rice straw biomass by selective removal of lignin. Biotechnol Bioeng., 109(10), 2484-2493.

38. Huang, Y.-F., Chiueh, P.-T., Lo, S.-L., 2016. A review on microwave pyrolysis of lignocellulosic biomass. Sustain. Environmental Res., 26, 103-109.

39. Tu, W-C., Hallett, J.P., 2019. Recent advances in the pretreatment of lignocellulosic biomass. Curr. Opin. Green Sustain. Chem., 20, 11-17.

40. Jedvert, K., Heinze, T., 2017. Cellulose modification and shaping-a review. J. Polym. Eng., 37, 845-860.

41. Jordan, A., Gathergood, N., 2015. Biodegradation of ionic liquids - a critical review. Chem. Soc. Rev., 44, 8200.

42. Kalita, E., Nath, B.K., Deb, P., Agan, F., Islam, M.R., Saikia, K., 2015. High quality fluorescent cellulose nanofibers from endemic rice husk: isolation and characterization. Carbohydr. Polym., 122, 308-313.

43. Kang, S., Fu, J., Zhang, G., 2018. From lignocellulosic biomass to levulinic acid: a review on acid-catalyzed hydrolysis. Renew. Sustain. Energy Rev., 94, 340-362.

44. Kassaye, S., Pant, K., Jain, S., 2017. Hydrolysis of cellulosic bamboo biomass into reducing sugars via a combined alkaline solution and ionic liquid pretreament steps. Renew. Energy, 104, 177-184.

45. Kim, D., 2018. Physico-Chemical Conversion of Lignocellulose: Inhibitor Effects and Detoxification Strategies: A Mini Review. Molecules. 23(2), 309.

46. Klein-Marcuschamer, D., Simmons, B.A., Blanch, H.W., 2011. Techno-economic analysis of a lignocellulosic ethanol biorefinery with ionic liquid pre-treatment. Biofuels Bioprod. Bioref., 5, 562-569. 
47. Konda, N.M., Shi, J., Singh, S., Blanch, H.W., Simmons, B., Klein-Marcuschamer, D., 2014. Understanding cost drivers and economic potential of two variants of ionic liquid pretreatment for cellulosic biofuel production. Biotechnol. Biofuels, 7, 86.

48. Kumar, A.K., Sharma, S., 2017. Recent updates on different methods of pretreatment of lignocellulosic feedstocks: a review. Bioresour. Bioprocess, 4, p. 7.

49. Lavarda, G., Morales-delaRosa, S., Centomo, P., Campos-Martin, J.M., Zecca, M., Fierro, J.L.G., 2019. Gel-Type and macroporous cross-linked copolymers functionalized with acid groups for the hydrolysis of wheat straw pretreated with an ionic liquid. Catalysts, 9, 675 .

50. Li, H-Y., Chen, X., Wang, C-Z., Sun, S-N., Sun, R-C., 2016. Evaluation of the two-step treatment with ionic liquids and alkali for enhancing enzymatic hydrolysis of eucalyptus: chemical and anatomical changes. Biotechnol. Biofuels, 9, 166.

51. Li, Y., Liu, X., Zhang, S., Yao, Y., Yao, X., Xu, J., et al., 2015. Dissolving process of a cellulose bunch in ionic liquids: a molecular dynamics study. Phys. Chem. Chem. Phys. $17,17894-17905$.

52. Li, Y., Wang, J., Liu, X., Zhang, S., 2018. Towards a molecular understanding of cellulose dissolution in ionic liquids: anion/cation effect, synergistic mechanism and physicochemical aspects. Chem Sci., 9(17), 4027-4043.

53. Liu, Y., Guo, L., Wang, L., Zhan, W., Zhou, H., 2017. Irradiation pretreatment facilitates the achievement of high total sugars concentration from lignocellulose biomass. Bioresour. Technol., 232, 270-277.

54. Liu, Y.R., Thomsen, K., Nie, Y., Zhang, S.-J. and Meyer, A. S., 2016. Predictive screening of ionic liquids for dissolving cellulose and experimental verification. Green Chem. 18, 6246-6254. 
55. Liu, Z., Li, L., Liu, C., Xu. A., 2018. Pretreatment of corn straw using the alkaline solution of ionic liquids. Bioresour. Technol., 260, 417-420.

56. Luo, M., Tian, D., Shen, F., Hu, J., Zhang, Y., Yang, G., Zeng, Y., Deng, S., Hu, Y.A., 2019. Comparative Investigation of H2O2-Involved Pretreatments on Lignocellulosic Biomass for Enzymatic Hydrolysis. Biomass Convers. Bior., 9, 321-331.

57. Ma, H.H., Zhang, B.X., Zhang, P., Li, S., Gao, Y. F., Hu, X.M., 2016. An efficient process for lignin extraction and enzymatic hydrolysis of corn stalk by pyrrolidonium ionic liquids. Fuel Process. Technol., 148, 138-145.

58. Ma, X., Long, Y., Duan, C., Lin, X., Cao, S., Chen, L., Ni, Y., 2017. Facilitate hemicelluloses separation from chemical pulp in ionic liquid/water by xylanase pretreatment. Ind. Crops Prod. 109, 459-463.

59. Madanayake, B.N., Gan, S., Eastwick, C., Ng, H.K., 2017. Biomass as an energy source in coal co-firing and its feasibility enhancement via pre-treatment techniques. Fuel Process. Technol., 159, 287-305.

60. Mai, N.L., Ha, S.H., Koo, Y., 2014. Efficient pretreatment of lignocellulose in ionic liquids/cosolvent for enzymatic hydrolysis enhancement into fermentable sugars. Process. Biochem., 49, 1144-1151.

61. Mai, N.L., Koo, Y-M., 2016. Computer-aided design of ionic liquids for high cellulose dissolution. ACS Sustain. Chem. Eng., 4, 541-547.

62. Mao, J., Abushammala, H., Pereira, L.B., Laborie, M., 2016. Swelling and hydrolysis kinetics of Kraft pulp fibers in aqueous 1-butyl-3-methylimidazolium hydrogen sulfate solutions. Carbohydrate Polym., 153, 284-291.

63. Masiutin, I., Golyshkin, A., Litvin, A., Novikov, A., Kotelev, M., Ivanov, E., Vinokurov, V., 2018. Pretreatment of cellulosic substrates with acetate-and chloride-based ionic liquids and their mixtures. Cell. Chem. Technol., 52, 1-2. 
64. Minnick, D. L., Flores, R. A., DeStefano, M. R., \& Scurto, A. M., 2016. Cellulose Solubility in Ionic Liquid Mixtures: Temperature, Cosolvent, and Antisolvent Effects. J. Phys. Chem. B., 120(32), 7906-7919.

65. Mohammadi, M., Shafiei, M., Karimi, K., Abdolmaleki, A., Mikkola, J-P., Larrson, C., 2019. Improvement of ethanol production from birch and spruce pretreated with 1-H-3methylmorpholinium chloride. Electron. J. Biotechn., 41, 95-99.

66. Mohan, M., Deshavath, N.N., Banerjee, T., Goud, V.V., Dasu, V.V., 2018. Ionic Liquid and Sulfuric Acid-Based Pretreatment of Bamboo: Biomass Delignification and Enzymatic Hydrolysis for the Production of Reducing Sugars. Ind. Eng. Chem. Res., 57(31), 10105-10117.

67. Mohtar, S., Busu, T.M.T., Md Noor, A., Shaari, N., Yusoff, N., Khalil, B.M.A., et al., 2015. Extraction and characterization of lignin from oil palm biomass via ionic liquid dissolution and non-toxic aluminium potassium sulfate dodecahydrate precipitation processes. Bioresour. Technol., 192, 212-218.

68. Muhammad, N., Man, Z., Bustam, M.A., Mutalib, M.I.A., Rafq, S., 2013. Investigations of novel nitrile-based ionic liquids as pre-treatment solvent for extraction of lignin from bamboo biomass. J. Ind. Eng. Chem., 19, 207-214.

69. Muhammad, N., Man, Z., Bustam, M.A., Mutalib, M.I.A., Wilfred, C.D., Rafq, S., 2011. Dissolution and delignification of bamboo biomass using amino acid-based ionic liquid. Appl. Biochem. Biotechnol., 165, 998-1009.

70. Muranaka, Y., Nakagawa, H., Hasegawa, I., Maki, T., Hosokawa, J., Ikuta, J., Mae, K., 2017. Lignin-based resin production from lignocellulosic biomass combining acidic saccharification and acetone-water treatment. Chem. Eng. J., 308, 754-759.

71. Mussatto, S.I., Bikaki, N., 2016. Technoeconomic Consideration from Biomass Fractionation in a Biorefinery Context. In Biomass Fractionation Technologies from a 
Lignocellulosic Feedstock Based Biorefinery; Mussatto, S.I., Ed.; Elsevier Inc.: Amsterdam, The Netherlands, pp. 587-610.

72. Naghshbandi, M.N., Tabatabaei, M., Aghbashlo, M., Gupta, V.K., Sulaiman, A., Karimi, K., Moghimi, H., Maleki, M., 2019. Progress toward improving ethanol production through decreased glycerol generation in Saccharomyces cerevisiae by metabolic and genetic engineering approaches. Renew. Sust. Energ. Rev., 115, 109353.

73. Nargotra, P., Sharma, V., Gupta, M., Kour, S., Kumar Bajaj, B., 2018. Application of ionic liquid and alkali pretreatment for enhancing saccharification of sunflower stalk biomass for potential biofuel-ethanol production. Bioresour. Technol., 267, 560-568.

74. Ninomiya, K., Abe, M., Tsukegi, T., Kuroda, K., Omichi, M., Takada, K., et al., 2017. Ionic liquid pre-treatment of bagasse improves mechanical property of bagasse/polypropylene composites. Ind. Crops Prod., 109, 158-162.

75. Oleskowicz-Popiel, P., Klein-Marcuschamer, D., Simmons, BA., Blanch, H.W., 2014. Lignocellulosic ethanol production without enzymes - technoeconomic analysis of ionic liquid pretreatment followed by acidolysis. Bioresour. Technol., 158, 294-299.

76. Papa, G., Feldmana, T., Sale, K.L., Adani, F., Singh, S., Simmons, B.A., 2017. Parametric study for the optimization of ionic liquid pretreatment of corn stover. Bioresour. Technol., 241, 627-637.

77. Parthasarathi, R., Sun, J., Dutta, T., Sun, N., Pattathil, S., Murthy Konda, N.V.S.N., et al. 2016. Activation of lignocellulosic biomass for higher sugar yields using aqueous ionic liquid at low severity process conditions. Biotechnol. Biofuels., 9, p. 160.

78. Paul, A., Muthukumar, S., Prasad, S., 2020. Review Room-temperature ionic liquids for electrochemical application with special focus on gas sensors. J. Electrochem. Soc., 167 037511. 
79. Pedersen, J., Perez, B., Guo, Z., 2019. Stability of cellulase in ionic liquids: correlations between enzyme activity and COSMO-RS descriptors. Scientific Reports 9(1).

80. Perez-Pimienta, J.A., Flores-Gomez, C.A., Ruiz, H.A., Sathitsuksanoh, N., Balan, V., Sousa, L.D.C., Dale, B.E., Singh, S., Simmons, B.A., 2016. Evaluation of agave bagasse recalcitrance using AFEXTM, autohydrolysis, and ionic liquid pretreatments. Bioresour. Technol., 211, 216-223.

81. Perez-Rodriguez, N., Garcia-Bernet, D., Dominguez, J.M., 2017. Extrusion and Enzymatic Hydrolysis as Pretreatments on Corn Cob for Biogas Production. Renew. Energy, 107, 597-603.

82. Rabideau, B.D., Agarwal, A., Ismail, A.E., 2014. The role of the cation in the solvation of cellulose by imidazolium-based ionic liquids. J. Phys. Chem. B., 118, 1621-1629.

83. Raj, T., Gaur, R., Lamba, B.Y., Singh, N., Gupta, R.P., Kumar, R., et al., 2018. Characterization of ionic liquid pretreated plant cell wall for improved enzymatic digestibility. Bioresour. Technol., 249, 139-145.

84. Raj, T., Kapoor, M., Semwal, S., Sadula, S., Pandey, V., Gupta, R.P., Kumar, R., Tuli, D.K., Das, B.P., 2016. The cellulose structural transformation for higher enzymatic hydrolysis by ionic liquids and predicting their solvating capabilities. J. Clean. Prod., 13, 1005-1014.

85. Ralph, E.H.S., 2014. Bioenergy options for a cleaner environment: In developed and developing countries. Elsevier Science, Palmerston North, New Zealand, p.198.

86. Reddy, K.O., Maheswari, C.U., Dhlamini, M.S., Mothudi, B.M., Kommula, V.P., Zhang, J., et al., 2018. Extraction and characterization of cellulose single fibers from native African napier grass. Carbohydr. Polym., 188, 85-91. 
87. Rigual, V., Santos, T.M., Dominguez, J.C., Alonso, M.V., Oliet, M., Rodriguez, F., 2017. Combining autohydrolysis and ionic liquid microwave treatment to enhance enzymatic hydrolysis of Eucalyptus globulus wood. Bioresour. Technol., 251, 197-203.

88. Saha, K., Sikder, J., Diwedi, P., Ghosh, A., Chakraborty, S., Mukherjee, D., Calabro, V. 2018. Improving Cellulose Structure for Bioconversion: Sugarcane Bagasse Pretreatment Accompanied by Lignin Recovery and Ionic Liquid Recycle. Adv. Sci. Technol. Innovation, 1155-1156.

89. Sen, S.M., Binder, B.J., Raines, R.T., Maravelias, T.C., 2012. Conversion of biomass to sugars via ionic liquid hydrolysis: process synthesis and economic evaluation. Biofuels, Bioprod. Bioref., 6, 444-452.

90. Settanni, G., Zhou, J., Suo, T., Schottler, S., Landfester, K., Schmid, F., et al., 2014. Inexpensive ionic liquids: [HSO4]- based solvent production at bulk scale. Green Chem., $16,3098-3106$.

91. Shah, T.A., Ullah, R., 2019. Pretreatment of Wheat Straw with Ligninolytic Fungi for Increased Biogas Productivity. Int. J. Environ. Sci. Technol., 1-12.

92. Singh, J. K., Sharma, R.K., Ghosh, P., Kumar, A., Khan, M.L., 2018. Imidazolium Based Ionic Liquids: A Promising Green Solvent for Water Hyacinth Biomass Deconstruction. Front. Chem., 6, 548.

93. Smuga-Kogut, M., Zgorska, K., Kogut, T., Kukielka, K., Wojdalski, J., Kupczyk, A., et al., 2017. The use of ionic liquid pre-treatment of rye straw for bioethanol production. Fuel, 191, 266-274.

94. Srivastava, N., Rathour, R., Jha, S., Pandey, K., Srivastava, M., Thakur, V.K., Sengar, R.S., Gupta, V.K., Mazumder, P.B., Khan, A.F., Mishra, P.K., 2019. Microbial beta glucosidase enzyme: Recent advances in biomass conversation for biofuels application. Biomolecules, 9, 220. 
95. Stanton, J., Xue, Y., Pandher, P., Malek, L., Brown, T., Hu, X., et al., 2018. Impact of ionic liquid type on the structure, morphology and properties of silk-cellulose biocomposite materials. Int. J. Biol. Macromol., 108, 333-341.

96. Stepan, A. M., Monshizadeh, A., Hummel, M., Roselli, A., Sixta, H., 2016. Cellulose fractionation with IONCELL-P. Carbohyd. Polym., 150, 99-106.

97. Sun, J., Konda, N.V.S.N.M., Parthasarathi, R., Dutta, T., Valiev, M., Xu, F., Simmons, B.A., Singh, S., 2017. One-pot integrated biofuel production using low-cost biocompatible protic ionic liquids. Green. Chem., 19, 3152-3163.

98. Sun, N., Parthasarathi, R., Socha, A.M., Shi, J., Zhang, S., Stavila, V., Sale, K.L., Simmons, B.A., Singh, S., 2014. Understanding pre-treatment efficacy of four cholinium and imidazolium ionic liquids by chemistry and computation. Green Chem., 16, 25462557.

99. Sun, X., Sun, X., Zhang, F., 2016. Combined pretreatment of lignocellulosic biomass by solid base (calcined $\mathrm{Na}_{2} \mathrm{SiO}_{3}$ ) and ionic liquid for enhanced enzymatic saccharification. RSC Advances, 6(101), 99455-99466.

100. Tiong, Y.W., Yap, C.L., Gan, S., Yap, W.S.P., 2017. One-pot conversion of oil palm empty fruit bunch and mesocarp fiber biomass to levulinic acid and upgrading to ethyl levulinate via indium trichloride-ionic liquids. J. Clean Prod., 168, 1251-1261.

101. Tomimatsu, Y., Suetsugu, H., Yoshimura, Y., \& Shimizu, A., 2019. The solubility of cellulose in binary mixtures of ionic liquids and dimethyl sulfoxide: Influence of the anion. J. Mol. Liq., 279, 120-126.

102. Torr, K.M., Love, K.T., Simmons, B.A., Hill, S.A., 2016. Structural features affecting the enzymatic digestibility of pine wood pretreated with ionic liquids. Biotechnol. Bioeng., 113, 540-549. 
103. Tsapekos, P., Kougias, P.G., Angelidaki, I., 2018. Mechanical Pretreatment for Increased Biogas Production from Lignocellulosic Biomass; Predicting the Methane Yield from Structural Plant Components. Waste Manag., 78, 903-910.

104. Vieiraa, S., Barros, M.V., Sydney, A.C.N., Piekarski, C.M., de Francisco, A.C., Vandenberghe, L.P.d-S., Sydney, E.B., 2019. Sustainability of sugarcane lignocellulosic biomass pretreatment for the production of bioethanol. Bioresour. Technol., 122635.

105. Williams, C.L., Li, C., Hu, H., Allen, J.C., Thomas, B.J. 2018. Three Way Comparison of Hydrophilic Ionic Liquid, Hydrophobic Ionic Liquid, and Dilute Acid for the Pretreatment of Herbaceous and Woody Biomass. Front. Energy. Res. 6.

106. Wright, M., Brown, R.C., 2007. Establishing the optimal sizes of different kinds of biorefineries. Biofuels, Bioprod. Bioref., 1, 191-200.

107. Xiong, Y., Zhang, Z., Wang, X.L., Liu, B., Lin, J., 2014. Hydrolysis of cellulose in ionic liquids catalyzed by a magnetically-recoverable solid acid catalyst. Chem. Eng. J., 235, 349-355.

108. Xu, J., Liu, B., Hou, H., Hu, J., 2017. Pretreatment of eucalyptus with recycled ionic liquids for low-cost biorefinery. Bioresour. Technol., 234, 406-414.

109.Xue, Z., Zhao, X., Sun, R.C., Mu, T., 2016. Biomass-derived r-valerolactone-based solvent systems for highly efficient dissolution of various lignins: Dissolution behavior and mechanism study. ACS Sustain. Chem. Eng., 4, 3864-3870.

110. Yang, H., Shi, Z., Xiong, L., 2016. Ionic liquids assisted alkaline fractionation enhanced triploid poplar bioconversion for bioethanol production. Wood Res., 61(1), 83-94.

111. Yavir, K., Marcinkowski, L., Marcinkowska, R., Namiesnik, J., Kloskowski, A., 2018. Analytical applications and physicochemical properties of ionic liquid-based hybrid materials: A review. Analytica Chimica Acta, S0003-2670(18)31303-5 
112. Yoo, C.G., Pu, Y., Ragauskas, A.J., 2017. Ionic liquids: Promising green solvents for lignocellulosic biomass utilization. Curr. Opin. Green Sustain. Chem., 5, 5-11.

113. Yu, J., Paterson, N., Blamey, J., Millan, M., 2017. Cellulose, xylan and lignin interactions during pyrolysis of lignocellulosic biomass. Fuel, 191, 140-149.

114.Zakaria, S.M., Idris, A., Alias, Y., 2017. Lignin Extraction from Coconut Shell Using Aprotic Ionic Liquids. BioResources 12(3), 5749-5774.

115.Zhang, J., Li, J., Tang, Y., Lin, L., Long, M., 2015. Advances in catalytic production of bio-based polyester monomer 2, 5 furan dicarboxylic acid derived from lignocellulosic biomass. Carbohydr. Polym., 130, 420-428.

116.Zhang, Q., Hu, J., Lee, D.J., 2017. Pre-treatment of biomass using ionic liquids: research updates. Renew. Energy., 111, 77-84.

117.Zhang, Y., Huo, F., Wang, Y., Xia, Y., Tan, X., Zhang, S., and He, H., 2019. Theoretical Elucidation of $\beta-\mathrm{O}-4$ Bond Cleavage of Lignin Model Compound Promoted by Sulfonic Acid-Functionalized Ionic Liquid. Frontiers in chemistry, 7, 78.

118.Zhuang, X., Wang, W., Yu, Q., Qi, W., Wang, Q., Tan, X., Zhou, G., Yuan, Z., 2016. Liquid hot water pre-treatment of lignocellulosic biomass for bioethanol production accompanying with high valuable products. Bioresour. Technol., 199, 68-75.

\section{Figure Captions}

Fig. 1. Correlation of Lignin and Cellulose solubilization with Kamlet-Taft Basicity

Fig. 2. Ionic liquid-based pre-treatment pathways of lignocellulosic biomass 